\title{
The quality of great scallop (Pecten maximus) sperm after thawing
}

\author{
Suquet Marc ${ }^{1,{ }^{*}}$, Gourtay Clémence ${ }^{1}$, Donval Anne ${ }^{2}$, Le Goïc Nelly ${ }^{2}$, Quere Claudie ${ }^{3}$, Malo Florent ${ }^{1}$, \\ Le Grand Jacqueline ${ }^{1}$, Ratiskol Dominique ${ }^{1}$, Mingant Christian ${ }^{1}$, Fauvel Christian ${ }^{4}$ \\ ${ }^{1}$ Ifremer, UMR 6539, PFOM Department, Station Expérimentale d'Argenton, Argenton, France \\ 2 IUEM, UMR 6539, Lemar, Technopole Brest Iroise, Plouzané, France \\ 3 Ifremer, UMR 6539, PFOM Department, Technopole Brest-Iroise, Plouzané, France \\ ${ }^{4}$ Ifremer, UMR 248, Marbec, Station Ifremer, Palavas, France \\ *Corresponding author : Marc Suquet, email address : msuquet@ifremer.fr
}

\begin{abstract}
:
Most publications devoted to the cryopreservation of mollusc sperm have focused on the definition of technical protocols, avoiding the description of sperm quality after thawing. The present study investigated the effects of cryopreservation on sperm quality in the great scallop. Wild scallop were fished during the natural spawning period and conditioned in the hatchery before use. Sperm samples were obtained after intragonadal injection of serotonin and cryopreserved using a previously published protocol. Sperm quality was assessed using a panel of four parameters: sperm motility characteristics, using a a computer assisted sperm analysis plugin with Image $\mathrm{J}$, intracellular ATP content using an ATP-Lite kit, sperm integrity, using flow cytometry and sperm morphology, using transmission electron microscopy. For each parameter, fresh (control) and thawed spermatozoa were compared. A significant decrease of both the percentage of motile spermatozoa (reduction: $75 \%$ ) and sperm swimming speed $(86 \%)$ were observed for thawed sperm compared with fresh sperm. The percentage of living spermatozoa, as assessed using flow cytometry, was significantly lower for thawed sperm $(72.4 \pm 2.5 \%)$ compared with fresh sperm $(86.4 \pm 1.1)$. However, no significant difference of intracellular sperm ATP content was observed between fresh and thawed sperm. Post thawing, while some spermatozoa showed little or no morphological differences compared with fresh sperm, others had undergone drastic changes, including swelling of the plasma membrane, structural alterations of the chromatin and damage to mitochondria. In conclusion, the descriptive parameters studied in the present work showed that the quality of thawed great scallop sperm was lower than that of fresh cells but was still sufficient for use in aquaculture programs and sperm cryobanking for this species.
\end{abstract}




\section{Highlights}

- Post thawing, scallop sperm swimming characteristics were decreased. The percentage of living spermatozoa was significantly lower for thawed sperm. V Various morphological changes were observed using electron microscopy. Although decreased, the quality of thawed scallop sperm was sufficient for cryobanking.

Keywords : Pecten maximus, Reproduction, Gamete, Sperm, Cryopreservation

\section{Introduction}

Compared with fish species, sperm cryopreservation research has only been conducted on a limited number of molluscs. This can be explained by the frequent use of traditional rearing techniques with spat mainly collected from the wild rather than obtained from hatchery rearing. However, recent trends in mollusc farming, including breeder selection, creation of special lines and induction of triploids, have boosted the development of hatcheries. The research effort on sperm cryopreservation was first focused on Pacific oyster (Crassostrea gigas) because of its high commercial value. Since the first study on this species (Lannan, 1971), more than 50 papers have been published on cryopreservation of Pacific oyster sperm (for review see Hassan et al., 2015).

Most publications devoted to the cryopreservation of mollusc sperm have focused on the definition of technical protocols, including specific aspects such as the nature and the concentration of the cryoprotectant, the composition of the extender, and the definition of the cooling and thawing rates (Chao and Liao, 2001; Gwo, 2000). After thawing, sperm quality is generally described using only a small number of parameters, most often confined to the percentage of motile spermatozoa and their fertilization capacity (Kawamoto et al., 2007; Vitiello et al., 2011). However, a wide range of descriptive parameters is available, including the assessment of fine movement parameters using Computer Assisted Sperm Analysis (CASA) devices, cell integrity using ultrastructure or flow cytometry, sperm functioning with intracellular ATP content or fertilization capacity and DNA 
damage using Tunel or SCSA (Sperm Chromatin Structure Assay), as suggested for fish sperm (Cabrita et al., 2010; Fauvel et al., 2010). The effects of sperm cryopreservation on sperm quality were investigated in Greenshell mussel (Perna canaliculus), using a panel of complementary parameters describing the different types of damage to sperm function: DNA damage, sperm viability, motility and fertility, showing that freezing and thawing had adverse effects on all these parameters (Smith et al., 2012).

Great scallop is a functional hermaphrodite, both mature ovaries and testes being present during the spawning period and spermatozoa and oocytes being released by a single animal (Devauchelle and Mingant, 1991). Investigations on scallop sperm biology remain limited: the mature spermatozoon has a bullet-shaped head, a short acrosome and can be considered as being of the primitive type (Dorange and Le Pennec, 1989). A sperm "maturation process" along the genital ducts has been suggested. Sperm can be collected after intragonadal serotonin injection or thermal shock. Sperm movement can be activated by dilution in seawater and movement duration is long, lasting 4 to 10 h (Faure et al., 1994). Recently, a sperm cryopreservation protocol was published (Suquet et al., 2014), in which the percentage of motile spermatozoa decreased from fresh $(80 \pm 4 \%)$ to thawed sperm $(11 \pm 2 \%)$. However, the effects of cryopreservation on thawed sperm quality were not investigated. The present work aims to describe the quality of great scallop sperm after thawing and to compare it with fresh sperm, using a panel of descriptive parameters including sperm motility, viability, intracellular ATP content and morphology.

\section{Material and methods}

\subsection{Animals}

Adult great scallops (mean weight \pm SEM: $91.2 \pm 2.9 \mathrm{~g}$ ) were captured by divers in the bay of Brest (Finistère, France) during the natural spawning period (May to October; Paulet et al., 1988). The scallops were then transferred to the Argenton experimental hatchery (Ifremer) and maintained in a $600 \mathrm{~L}$ raceway $\left(17^{\circ} \mathrm{C}\right.$, salinity 34.0$)$ where they were fed daily on a mixture of microalgae (Isochrysis 
84 85 86 87 88 89

102

103

104

105

106

108

109

galbana and Chaetoceros calcitrans) for one month. The sperm collection method and laboratory analysis are given briefly below as these were previously described in detail in Suquet et al. (2013 and 2014).

\subsection{Sperm collection}

The scallops were treated with $100 \mu 1$ of a $10 \mathrm{mM}$ serotonin solution (dilution in seawater) and injected in the testes. They were then transferred to $2 \mathrm{~L}$ beakers, filled with $0.5 \mathrm{~L}$ seawater $\left(19^{\circ} \mathrm{C}\right.$, filtered at $1 \mu \mathrm{m})$. Sperm shedding was observed at 10 to $30 \mathrm{~min}$ post injection and samples were pipetted directly from the sperm plume, to ensure a high concentration. Sperm samples were then stored at $4^{\circ} \mathrm{C}$ until use.

\subsection{Sperm cryopreservation}

Sperm samples were diluted v/v with a solution containing the saline solution DCSB4, as an extender (Paniagua-Chavez et al., 1998) and polyethylene glycol (PEG: 20\%), as a cryoprotectant. Straws $(500 \mu \mathrm{l})$ were cryopreserved on a tray floating $5.5 \mathrm{~cm}$ above liquid nitrogen (LN) for $10 \mathrm{~min}$ and then plunged into LN. The straws were then thawed in a water bath $\left(25^{\circ} \mathrm{C}, 15 \mathrm{~s}\right)$.

\subsection{Sperm quality assessment}

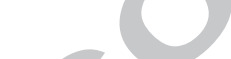

For each parameter, both fresh (control) and thawed spermatozoa were observed $(\mathrm{n}=6$ scallops). Sperm motility was assessed after $1: 625$ dilution in seawater $\left(19^{\circ} \mathrm{C}, 5 \mathrm{gL}^{-1} \mathrm{BSA}\right.$, Tris 20 mM, adjusted to $\mathrm{pH}$ 8.1). Sperm samples of $7 \mu 1$ were transferred to Fast-Read 102 cells (Biosigma®, Cona, Italy). Sperm motility was observed under a phase contrast microscope (Olympus BX51, $\times 10$ magnification), immediately and $1 \mathrm{~h}$ post sperm activation. The percentage of motile spermatozoa was visually estimated by counting $6 \times 30$ cells. Sperm movement was then recorded (Sony camera, 60 
111 frames $\mathrm{s}^{-1}, 10 \mathrm{~s}$ film duration). Sperm Velocity of the Average Path (VAP) was determined using a

112 CASA plug-in developed for Image J (Wilson-Leedy and Ingermann, 2007) and adapted to scallop 113 sperm (number of frames: 240 , minimum VAP for motile sperm: $3 \mu \mathrm{m} \mathrm{s}^{-1}$, minimum number of 114 spermatozoa observed: 30 ).

115 Intracellular sperm ATP content was assessed, immediately post activation, by 116 bioluminescence (ATP lite kit, Perkin Elmer, triplicates). Sperm concentration was determined by 117 counting in a Thomas-type hemocytometer, to express ATP content as nmole. $10^{-9}$ spermatozoa 118 (dilution $100 \mu 1$ sperm : $500 \mu 1$ seawater). Sperm viability was studied by flow cytometry (Guava EasyCyte Plus, Millipore), according

120 to Le Goïc et al. (2013), using dual staining (Live/Dead® Sperm Viability kit, Molecular probes).

121 Briefly, an aliquot of $200 \mu 1$ sperm (concentration: $10^{6}$ spermatozoa $\mathrm{ml}^{-1}$ ) was stained with both 122 SYBR-14, which penetrates cells with intact membranes, and Propidium iodide (PI), which stains cells 123 with membrane damage. The results were expressed as the percentage of living spermatozoa. 124 Furthermore, Side Scatter (SSC: relative sperm complexity) was also provided, to estimate sperm 125 morphological changes.

126 Then, changes in sperm morphology following cryopreservation were assessed using 127 transmission electron microscopy. Sperm samples of four scallops were fixed for $1 \mathrm{~h}$ in $3 \%$ 128 glutaraldehyde, buffered to $\mathrm{pH} 7.2$ with sodium cacodylate $\left(0.1 \mathrm{M}\right.$, adjusted to $1200 \mathrm{mOsmol} \mathrm{L}{ }^{-1}$ by 129 adding $\mathrm{NaCl})$. Samples were then centrifuged $(3000 \mathrm{rpm}, 10 \mathrm{~min})$ and post-fixed for $1 \mathrm{~h} \mathrm{in} 1 \%$ 130 osmium tetroxide. After dehydration through an ascending ethanol series, samples were embedded in 131 Epon resin. Ultrathin sections were stained with 7\% uranyl acetate lead citrate (Reynolds, 1963) and 132 examined using a Jeol TEM JM 1400.

133

134 2.5. Statistical analysis Results are presented as mean \pm SEM. Percentages of motile sperm were arcsin square root 137 transformed. Means were then compared (Statistica 6 software) using Student t-tests or one-way 
138 ANOVA. For ANOVA and when significant differences were observed $(\mathrm{P}<0.05)$, a Fisher a

139 posteriori test was used to compare the means.

140

141 3. Results

142

A significant decrease in the percentage of motile sperm $(\mathrm{P}<0.001)$ and VAP $(\mathrm{P}<0.001)$ was

144 observed for thawed sperm compared with fresh, both immediately and $1 \mathrm{~h}$ post sperm activation

145 (Fig.1a and b). For each treatment (fresh or thawed sperm), no significant differences were observed

146 between values assessed immediately and $1 \mathrm{~h}$ post sperm activation, for either the percentage of motile

147 sperm or VAP.

148 No significant difference of intracellular sperm ATP content was observed between fresh

$149\left(203.1 \pm 42.0\right.$ nmole. $10^{-9}$ spermatozoa $)$ and thawed sperm $\left(148.1 \pm 18.2\right.$ nmole. $10^{-9}$ spermatozoa $)$.

150 When assessed by flow cytometry, the percentages of living sperm were significantly higher

151 (P < 0.001) for fresh sperm compared with thawed (Fig. 2). Furthermore, significantly higher SSC

152 values $(\mathrm{P}<0.001)$ were observed for fresh sperm $(60.9 \pm 1.4)$ compared with thawed cells $(55.4 \pm 2.0)$.

153 The great scallop sperm head has a bullet shape and a reduced middle piece (Fig. 3a). A

154 conical acrosome is observed and the subacrosomal space is filled with a fine fibrillar material (Fig.

155 3b). The large nucleus contains dense granular chromatin, showing two depressions: an anterior one,

156 in the subacrosomal space and a posterior one, located at the basal pole, where the proximal centriole

157 is inserted (Fig. 3a). In the middle piece, four mitochondria can be identified (Fig. 3c). The distal

158 centriole is located in the middle piece, near the base of the flagellum (Fig. 3d). The axoneme contains

159 the typical ' $9+2$ ' pattern of tubules (Fig. 3h). The condition of the thawed spermatozoa was found to

160 be variable. For some spermatozoa, little or no morphological changes were noted, for the plasma

161 membrane, nucleus, mitochondria (Fig. 3e) or acrosome (Fig. 3f). On the other hand, drastic changes

162 could be distinguished in some spermatozoa: the plasma membrane could appear swollen, a wide

163 space appearing between the membrane and the nuclear surface (Fig. 3g). The flagellar plasma

164 membrane could also become swollen (Fig. 3h). Mitochondrial damage was observed: Fig. 3i and 3j

165 show enlarge intracristal spaces and plasma membrane disruption. Structural alterations of the 
166 chromatin also appeared, showing the presence of invaginations (Fig. 3i) and even sperm head

167 degeneration (Fig. 3j).

168

169

4. Discussion

170

effect on sperm movement characteristics, sperm morphology and sperm viability, but not on sperm intracellular ATP content.

A high recovery of thawed sperm (assessed as the percentage of motile sperm relative to a fresh control) is commonly observed in molluscs (Fig. 4), ranging from 65\% in Pacific oyster (Dong et al., 2005) to $23 \%$ in flat oyster (Horvath et al., 2012). Among the molluscs that have been studied, the limited survival of great scallop sperm after thawing (75\% reduction in the percentage of motile sperm) may be explained by the fact that only one other study to date has been devoted to sperm cryopreservation in this species (Suquet et al., 2014), compared with more than 50 studies on oyster species (for review see Hassan et al., 2015). Furthermore, sperm survival after thawing may vary between species, even close ones, since $51 \%$ survival was reported in another pectinid species, the Chilean scallop, Argopecten purpuratus (Espinoza et al., 2010). been studied in molluscs and, when assessed, often rely on subjective estimates with an arbitrary scale

186 (Dupré and Espinoza, 2004). The use of a CASA device enables objective estimation of sperm 187 movement speed: a 27\% reduction in thawed sperm VAP was reported in Greenshell mussels (Smith 188 et al., 2012), which is limited compared with the decrease of $86 \%$ assessed for great scallop sperm in 189 the present study.

The mean intracellular ATP content of fresh scallop sperm (203 \pm 14 nmole $10^{-9}$ sperm) was

191 found to be close to that previously estimated in the same species $\left(212 \pm 133\right.$ nmole $10^{-9}$ sperm;

192 Suquet et al., 2013) and to values reported in Pacific oyster (186 \pm 16 nmole $10^{-9}$ sperm; Boulais et al., 193 2015). The marked reduction of thawed scallop sperm movement characteristics observed in the 
194 present study cannot be explained by a decrease in sperm intracellular ATP content, because no

195 significant difference in this parameter was found between fresh and frozen cells. The intracellular

196 ATP content of frozen sperm had not been previously assessed in mollusc species. In marine fish, the

197 decrease of ATP content in thawed seabream (Sparus aurata) sperm samples compared with fresh

198 ones ranged from 50 to 95\%, affecting sperm movement characteristics (Cabrita et al., 2005). In

199 turbot (Scophthalmus maximus), a 40\% decrease in sperm ATP content was measured post thawing

200 (Dreanno et al., 1997). Sperm movement lasts a long time in scallop (8 to $10 \mathrm{~h}$ ), compared to values

201 recorded in marine fish species (a few minutes). This long movement duration suggests that scallop

202 sperm could partially restore the energy catabolized during the swimming phase. It appears that the

203 capacity for ATP regeneration is maintained in thawed scallop sperm because the percentage of motile

204 cells was not significantly different between measurements taken immediately post thawing and those

205 taken one hour later (Fig. 1a). The maintenance of ATP regeneration of thawed sperm is also sustained

206 by the absence of damage to mitochondria in some thawed spermatozoa, as observed by electron 207 microscopy.

208 Using flow cytometry, morphological damage to great scallop sperm was measured after 209 thawing, showing a 16\% decrease of sperm viability compared to fresh cells. Post thaw morphological 210 changes in scallop sperm were confirmed by the significant decrease of SSC values, suggesting 211 changes in cell complexity. Using electron microscopy, damage to the plasma membrane could be 212 observed post thawing. In Chilean scallop, swollen, folded or broken plasma membranes were 213 reported, after thawing (Espinoza et al., 2010). In blue mussel (Mytilus galloprovincialis) sperm 214 plasma membrane integrity decreased from $90 \%$ in fresh sperm to 21_25\% in thawed cells (Liu et al., 215 2016), suggesting a similar quality to that found in our work. Modifications of the plasma membrane 216 may affect sperm osmoregulation capacity and its fluidity. In human, sperm survival after thawing 217 depends on the fluidity of the plasma membrane in the fresh spermatozoa (Giraud et al., 2000), 218 suggesting that this membrane plays a key role during cryopreservation.

219 The fact that little or no damage to the acrosome and mitochondria were observed post 220 thawing means that a high fertilization capacity of great scallop cryopreserved sperm is maintained. In 221 a previous work, we demonstrated that the fertilization ability of thawed sperm was significantly lower 
222 than that of fresh sperm but, fertilization rates similar to those recorded using fresh sperm were 223 observed using a non-limiting sperm to oocyte ratio of 500 (Suquet et al., 2014).

224 In conclusion, the quality of thawed great scallop sperm was lessened compared with fresh 225 cells, including a decrease of sperm movement characteristics and sperm viability and damage to 226 sperm morphology. Further research is needed to improve sperm survival after thawing, considering 227 the quantity of cryoprotectant used and the incorporation of different components such as proteins and 228 sugars in the extender. However, a 20 to $30 \%$ percentage of motile spermatozoa is already sufficient 229 for use in aquaculture programs and sperm cryobanking of the great scallop.

\section{Acknowledgements}

The authors want to thank Stephane Pouvreau (Ifremer) and Matthias Huber (Ifremer) for 233 fishing the scallops. They also thank Gérard Sinquin (Université de Bretagne Occidentale) for help 234 with the electron microscopy study and Sébastien Hervé (Université de Bretagne Occidentale) for 235 photo processing. We thank Helen McCombie for help in editing the English. Financial support was 236 provided by CRB-anim infrastructure project, ANR-11-INBS-0003, funded by the French National 237 Research Agency in the frame of the "Investing for the Future program".

\section{References}

Boulais, M., Soudant, P., Le Goïc, N., Quere, C., Boudry, P., Suquet, M., 2015. Involvement of mitochondrial activity and OXPHOS in ATP synthesis during the motility phase of spermatozoa in the Pacific oyster (Crassostrea gigas). Biol. Reprod., 93, 1-7.

Cabrita, E., Robles, V., Rebordinos, L., Sarasquete, C., Herraez, M.P., 2005. Evaluation of DNA damage in rainbow trout (Oncorhynchus mykiss) and gilthead sea bream (Sparus aurata) cryopreserved sperm. Cryobiology 50, 144-153. 
250

251

252

253

254

255

256

257

258

259

260

261

262

263

264

265

266

267

268

269

270

271

272

273

274

275

276

277

Chao, N.H., Liao, I.C., 2001. Cryopreservation of finfish and shellfish gametes and embryos. Aquaculture 197, 161-189.

Devauchelle, N., Mingant, C., 1991. Review of the reproductive physiology of the scallop, Pecten maximus, applicable to intensive aquaculture. Aquat. Living Resour. 4, 41-51.

Di Matteo, O., Langellotti, A.L., Masullo, P., Sansone, G., 2009. Cryopreservation of the Mediterranean mussel (Mytilus galloprovincialis) spermatozoa. Cryobiology 58, 145-150.

Dong, Q., Huang C., Eudeline B., Tiersch T., 2005. Systematic factor optimization for cryopreservation of shipped sperm samples of diploid Pacific oysters, Crassostrea gigas. Cryobiology 51, 176-195.

Dorange, G., Le Pennec, M., 1989. Ultrastructural characteristics of spermatogenesis in Pecten maximus (Mollusca, Bivalvia). Inv. Reprod. Develop. 15, 109-117.

Dreanno, C., Suquet, M., Quemener, L., Cosson, J., Fierville, F., Normant, Y., Billard, R., 1997. Cryopreservation of turbot (Scophthalmus maximus) spermatozoa. Theriogenology 48, 589603.

Dupré, E., Espinoza, C., 2004. Congelamiento de espermatozoides del ostion del norte Argopecten purpuratus mediante congelator mecanico. Invest. Mar., Valparaiso 32, 3-9.

Espinoza, C., Valdivia, M., Dupré, E., 2010. Morphological alterations in cryopreserved spermatozoa of scallop Argopecten purpuratus. Lat. Am. J. Aquat. Res. 38, 121-128.

Faure, C., Devauchelle, N., Girard, J.P., 1994. Ionic factors affecting motility, respiration and fertilization rate of the sperm of the bivalve Pecten maximus (L.). J. Comp. Physiol. B. 164, 444-450.

Fauvel, C., Suquet, M., Cosson, J., 2010. Evaluation of fish sperm quality. J. Appl. Ichthyol. 26, 636643.

Giraud, M.N., Motta, C., Boucher, D., Grizard, G., 2000. Membrane fluidity predicts the outcome of cryopreservation of human spermatozoa. Human Reprod. 15, 2160-2164.

Gwo, J.C., 2000. Cryopreservation of aquatic invertebrate semen: a review. Aquac. Res. 31, 259-271.

Hassan, Md.M., Qin, J.G., Li, X., 2015. Sperm cryopreservation in oysters: A review of its current status and potentials for future application in aquaculture. Aquaculture, 438, 24-32. 
278 Horvath, A., Bubalo, A., Cucevié, A., Bartulovic, V., Kotrik, L., Urbanyi, B., Glamuzina, B., 2012.

279

280

281

282

283

284

285

286

287

288

289

290

291

292

293

294

295

296

297

298

299

300

301

302

303

304

305

Cryopreservation of sperm and larvae of the European flat oyster (Ostrea edulis). J. Appl. Ichthyol. 28, 948-951.

Kawamoto, T., Narita, T., Isowa, K., Aoki, H., Hayashi, M., Komaru, A., Ohta, H., 2007. Effects of cryopreservation methods on post-thaw motility of spermatozoa from the Japanese pearl oyster, Pinctada fucata martensi. Cryobiology 54, 19-26.

Lannan, J.E., 1971. Experimental self-fertilization of the Pacific oyster, Crassostrea gigas, utilizing cryopreserved sperm. Genet. 68, 599-601.

Le Goïc, N., Hégaret, H., Fabioux, C., Miner, P., Suquet, M., Lambert, C., Soudant, P., 2013. Impact of the toxic dinoflagellate Alexandrium catenella on Pacific oyster reproductive output: application of flow cytometry assays on spermatozoa. Aquat. Living Resour. 26, 221-228.

Liu, B., Liu, Y., Liu, S., Xu, T., Liu, Q., Li, X., 2016. Cryopreservation of strip spawned sperm using non-programmable freezing technique in the blue mussel Mytilus galloprovincialis. Aquac. Res., in press.

Narita, T., Kawamoto, T., Isowa, K., Aoki, H., Hayashi, M., Komura, A., Ohta, H., 2008. Fertility of cryopreserved spermatozoa of the Japanese pearl oyster, Pinctada fucata martensii. Aquaculture 275, 178-181.

Paniagua-Chavez, C.G., Buchanan, J.T., Tiersch, T., 1998. Effects of extender solutions and dilution on motility and fertilizing ability of Eastern oyster sperm. J. Shellfish Res. 17, 231-237.

Paulet, Y.M., Lucas, A., Gerard, A., 1988. Reproduction and larval development in two Pecten maximus (L.) populations from Brittany. J. Exp. Mar. Biol. Ecol. 119, 145-156.

Reynolds, E.S., 1963. The use of lead citrate at high $\mathrm{pH}$ as electron opaque stain in electron microscopy. J. Cell Biol. 17, 208-212.

Smith, J.F., Adams, S.L., McDonald, R.M., Gale, S.L., McGowan, L.T., Tervit H.R., 2012. Cryopreservation of Greenshell mussel (Perna canaliculus) sperm. II. Effect of cryopreservation on fertility, motility, viability and chromatin integrity. Aquaculture 364/365: $322-328$.

Suquet, M., Quéré, C., Mingant, C., Lebrun, L., Ratiskol, D., Miner, P., Cosson, J., 2013. Effect of 

of scallop (Pecten maximus) sperm. Aquat. Living Resour. 26, 215-220.

308

309

310

311

313

314

315

316

317
Suquet, M., Arsenault-Pernet, M.E.J., Ratiskol, D., Mingant, C., 2014. Cryopreservation of great scallop (Pecten maximus) sperm : effect of extender, cryoprotectant and cooling rate on sperm survival. Aquat. Living. Resour. 27, 35-40.

Vitiello, V., Carlino, P.A., Langelloti, A.L., Sansone, G., 2011. Effects of cooling and freezing on the motility of Ostrea edulis (L., 1758) spermatozoa after thawing. Cryobiology 63, 118-124.

Wilson-Leedy, J.G., Ingerman, R.L., 2007. Development of a novel CASA system based on open source software for characterization of zebrafish sperm motility parameters. Theriogenology 67, 661-672.

Yang, H., Hu, E., Cuevas-Uribe, R., Supan, J., Guo, X., Tiersch, T., 2012. High-throughput sperm cryopreservation of Eastern oyster Crassostrea virginica. Aquaculture 344-349, 223-230. 
Fig. 1. Effect of cryopreservation on great scallop sperm motility characteristics, assessed immediately

$321(0 \mathrm{~h})$ and $1 \mathrm{~h}$ post sperm activation $(\mathrm{n}=6$ scallops, mean \pm SEM, different letters indicate significantly 322 different results), a) percentage of motile spermatozoa, b) Velocity of the Average Path (VAP).

Fig. 2. Effect of cryopreservation on great scallop sperm integrity, as assessed by flow cytometry ( $\mathrm{n}=$ 6 scallops, mean \pm SEM, different letters indicate significantly different results).

327 Fig. 3. Effect of cryopreservation on great scallop sperm morphology, as assessed by transmission 328 electron microscopy ( $n=4$ scallops): $3 a \_d$ : fresh sperm, $3 e_{-} \mathrm{j}$ : thawed sperm: a) longitudinal section of spermatozoon, b) longitudinal section of acrosome (arrow: fine fibrillar material), c) cross section of middle piece, d) longitudinal section of middle piece, e) longitudinal section of spermatozoon, f) longitudinal section of acrosome, g) longitudinal section of spermatozoon (arrow: swelling of plasma membrane), h) cross section of flagellum, i) longitudinal section of spermatozoon (arrow: swelling of plasma membrane, double arrow: invagination of nucleus), j) longitudinal section of spermatozoa (double arrow: chromatin disintegration). a: acrosome, dc: distal centriole, f: flagellum, mi: mitochondria, n: nucleus, pc: proximal centriole.

Fig. 4. Effect of sperm cryopreservation on the percentage of great scallop motile spermatozoa

338 (percentage of fresh control measurement), in different mollusc species (best survival observed in 339 Pacific oyster, Crassostrea gigas: Dong et al., 2005; blue mussel, Mytilus galloprovincialis: Di Matteo 340 et al., 2009; Eastern oyster, Crassostrea virginica: Yang et al., 2012; Chilean scallop, Argopecten 341 purpuratus: Espinoza et al., 2010; pearl oyster, Pinctada fucata martensii: Narita et al., 2008; scallop: 342 present study; flat oyster, Ostrea edulis: Horvath et al., 2012). 
347

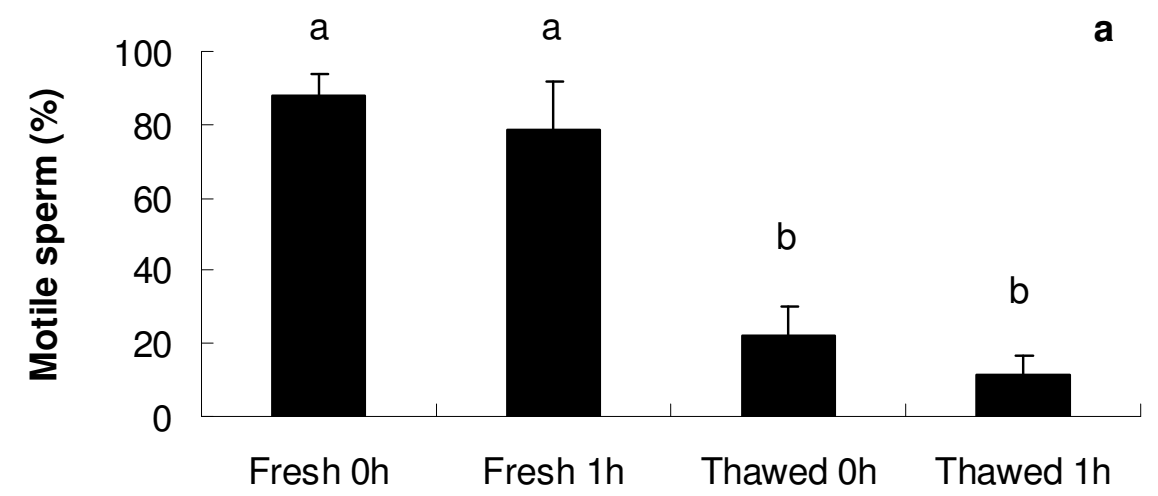

348

349

\section{Sperm}

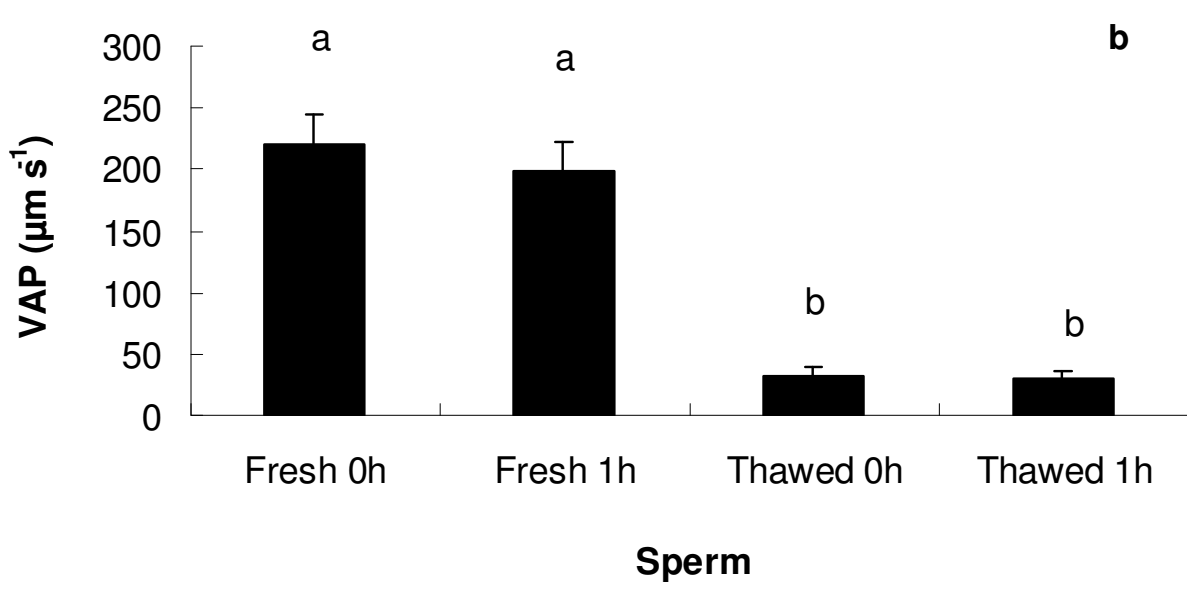

350

351

352

353 Fig. 1

354 
355

356

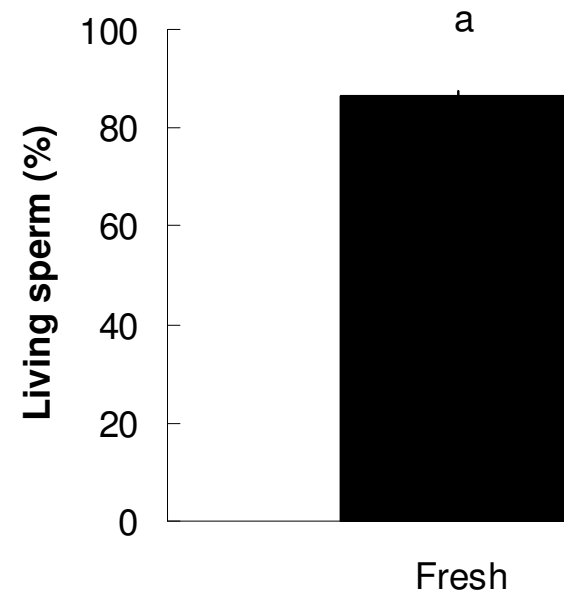

b

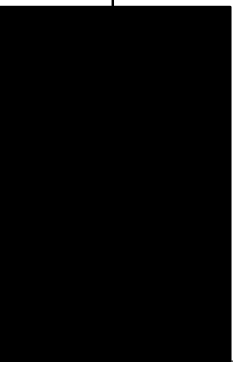

Thawed

Sperm

361

362

363 


\section{ACCEPTED MANUSCRIPT}
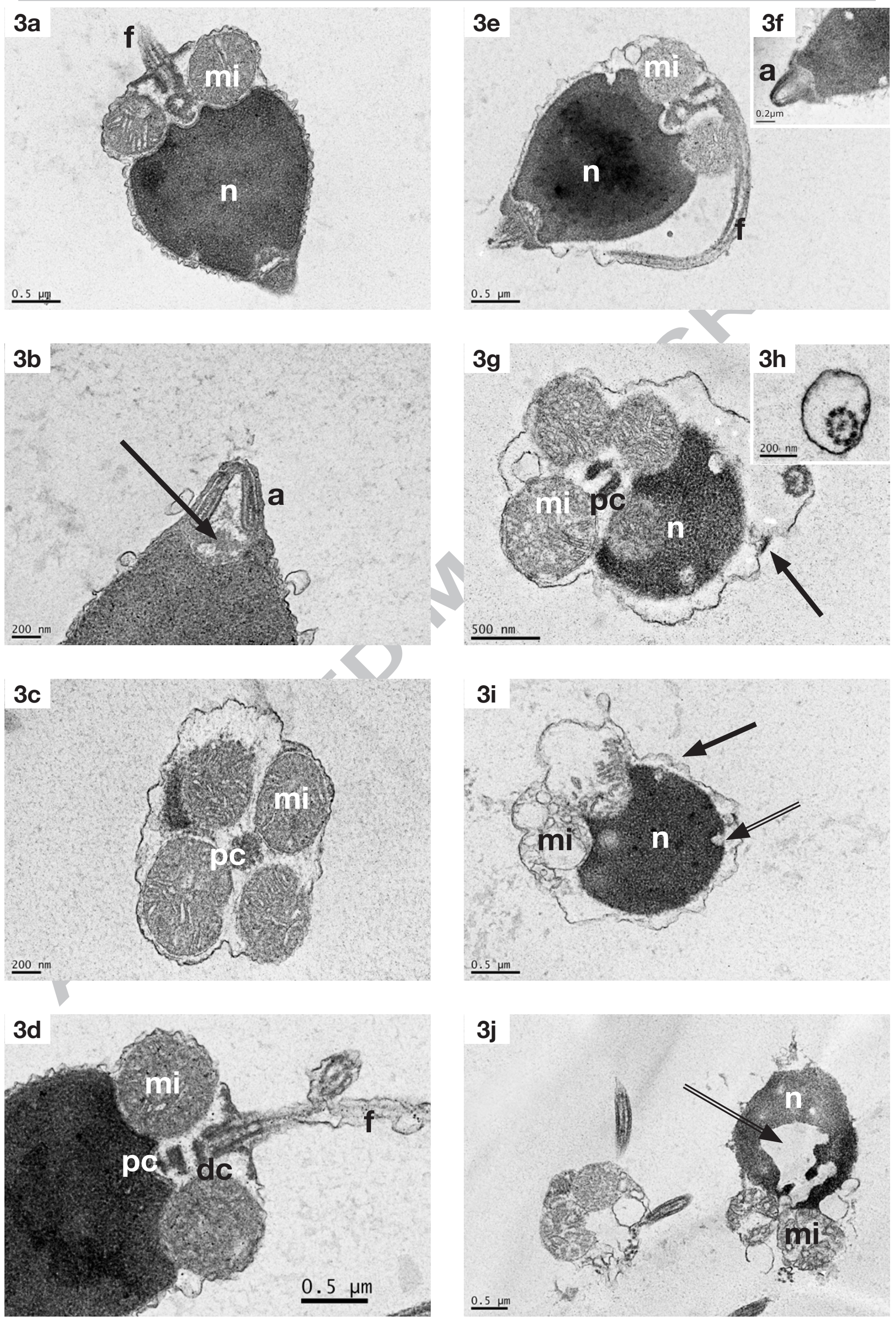
364

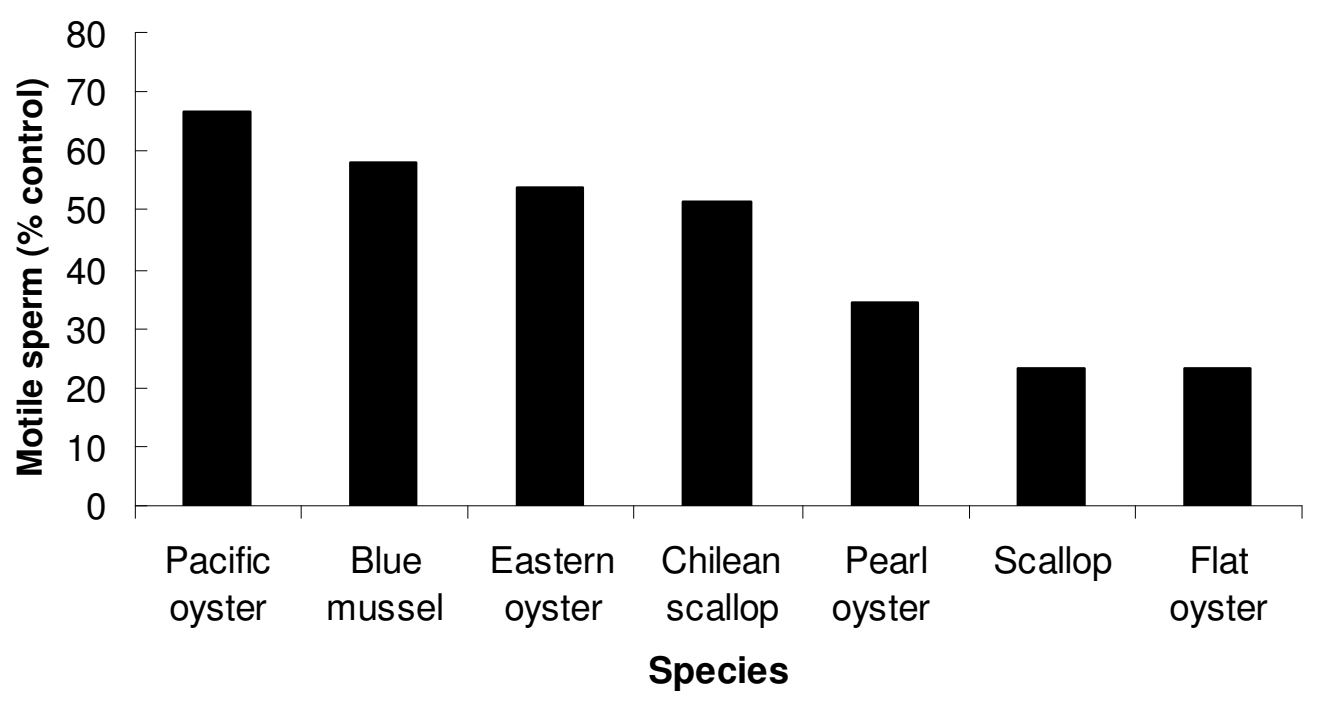

369 Fig. 4

370 